\title{
High-efficiency Technology of White OLEDs
}

\author{
Hiroya T suji, Kazuyuki Y amae, Varutt Kittichungchit, \\ Nobuhiro Ide and T akuya Komoda
}

\begin{abstract}
Panasonic Corporation, E co Solutions Company, Kadoma 571-8686, 0 saka, Japan
High-performance all-phosphorescent white devices on a light outcoupling substrate which comprised high-index materials were investigated. The two-unit device composed of the $\mathrm{red} / \mathrm{blue}$ and $\mathrm{red} / \mathrm{green}$ phosphorescent units on the light outcoupling substrate achieved high light coupling efficiency of $49 \%$. An electrically and optically optimized two-unit of all phosphorescent white OLED realized low driving voltage of $5.5 \mathrm{~V}$, high luminous efficacy of $114 \mathrm{Im} / \mathrm{W}$ and half decay lifetime of over $120,000 \mathrm{~h}$ at $1,000 \mathrm{~cd} / \mathrm{m}^{2}$.
\end{abstract}

Keywords: OLED; light extraction efficiency; outcoupling; refractive index; phosphorescent

\section{Introduction}

Recently, energy saving becomes one of the greatest concerns to conserve the global environment. Solid-state light emitting diode (LED) lighting applications dramatically prevailed in global market and they have already been familiar to us. Organic light emitting diode (OLED) is another candidate of solid-state device for next-generation lighting because it is superior to the conventional light sources due to its high design flexibility, thin appearance, light weight. We have already realized high luminous efficacy of $42 \mathrm{~lm} / \mathrm{W}$, long life time (LT50) of over $100,000 \mathrm{~h}$ and high color rendering index (CRI) of 90 at $1,000 \mathrm{~cd} / \mathrm{m}^{2}$ [1]. This device had the two-unit structure composed of red/green phosphorescent unit and blue fluorescent unit on a glass substrate with a light outcoupling film attached onto surface of the substrate. Typical structure of this system is shown in Fig. 1.

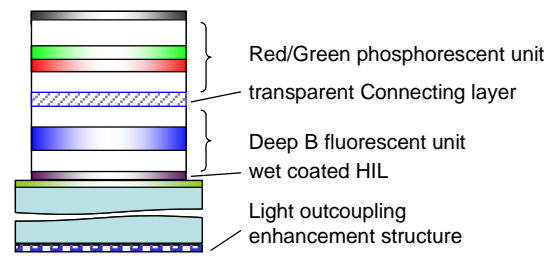

Fig. 1. Typical structure of the two-unit fluorescent/phosphorescent hybrid OLED.

$\begin{array}{llr}\text { Received } & \text { A pril } & 1,2013 \\ \text { Accepted } & \text { M ay } & 10,2013\end{array}$

W e have also developed light extraction technology focused on extracting waveguide mode [2], and applied original built-up light extraction substrate (BLES) based on high refractive index components to high performance all-phosphorescent devices. Cross section of the OLED on the BLES is shown in Fig. 2.

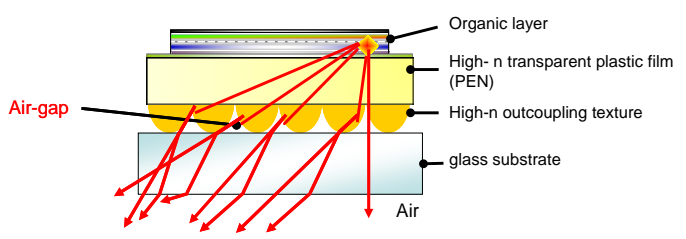

Fig. 2. Cross-sectional image of OLED on the BLES.

All-phosphorescent white OLED on the BLES has realized high efficacy of about $85 \mathrm{~lm} / \mathrm{W}$ and quite long half-decay lifetime of over $100,000 \mathrm{~h}$ at 1,000 $\mathrm{cd} / \mathrm{m}^{2}[3,4]$. In terms of efficiency, commercialized OLED has already exceeded that of incandescent bulb. However, it is yet insufficient for expected level as next-generation general lighting. Light outcoupling enhancement and high efficiency phosphorescent material is quite important technology in order to improve the performance of white OLED for lighting application [5-10].

In this paper, light extraction efficiency and structural design of two-unit all-phosphorescent 
white OLED with BLES were studied to obtain higher efficacy of over $100 \mathrm{~lm} / \mathrm{W}$.

\section{Optical design for OLED with BLES}

BLES comprises a transparent electrode, a high refractive index $(n=1.77$ at $550 \mathrm{~nm})$ polyethylene naphthalate (PEN) film with high-refractive index $(\mathrm{n}=1.77$ at $550 \mathrm{~nm})$ micro lens array (MLA) structure, and a glass substrate for encapsulation. A ir-gap exists between M LA and the glass substrate. According to high refractive index structure, light emitted from organic layers propagate in PEN and MLA without total internal reflection (TIR). The light is divided into transmitted diffraction and reflected diffraction at the interface of $M L A$ and the air-gap. Transmitted diffraction is extracted to the air without TIR at glass surfaces. Reflected diffraction is extracted through the multiple reflections in OLED and BLES, or absorbed. BLES has a potential for realizing more excellent light extraction efficiency with suppressing internal absorption since TIR is almost eliminated.

High absorption organic layers were carefully specified and replaced by lower absorption materials in the device. Comparison of light extraction structures (BLES and conventional outcoupling film) with different absorption devices are shown in Fig. 3. Optical enhancement of external quantum efficiency $(E Q E)$, which is in proportion to light extraction efficiency, was obviously improved with lower absorption. The trend was more dominant in BLES than conventional structure with external outcoupling film.

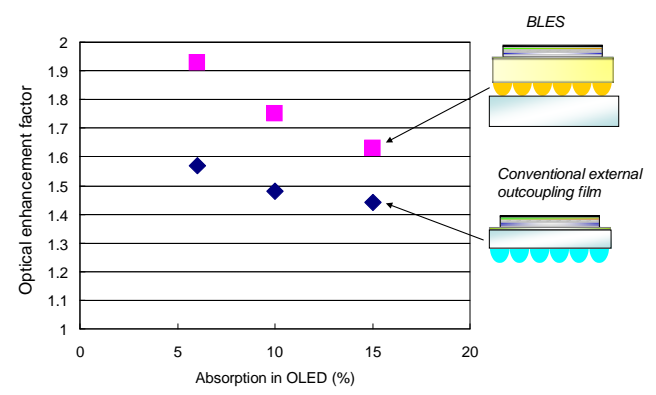

Fig. 3. Optical enhancement with lower absorption.

Internal light distribution in OLED with BLES was designed for high-n M LA. For example, wide elliptic pattern which was intensified wider angular was applied as shown in Fig. 4. Internal angular distribution pattern of OLED was measured by an optical system with high-n macro hemisphere lens which was sufficiently larger than emitting area to be available as point source, as shown in Fig. 5 . A bout $10 \%$ of optical enhancement was observed at the device with designed pattern because transmittance from high-n MLA to the air became more effective.

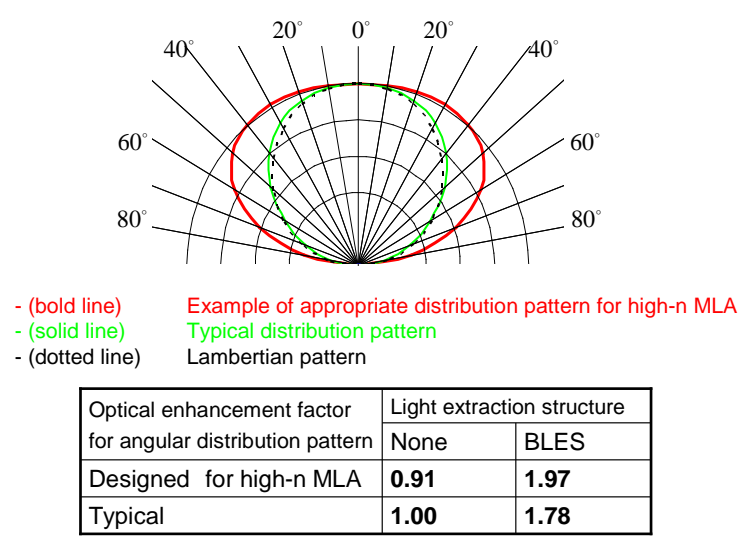

Fig. 4. Preferable light angular distribution for BLES.

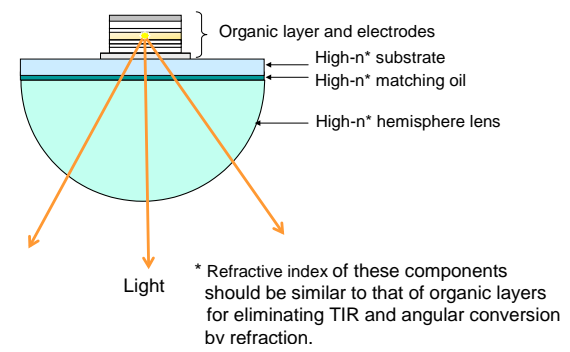

Fig. 5. Measurement system for internal distribution pattern.

\section{Two-unit all-phosphorescent white OLE D}

Two-unit all phosphorescent white OLEDs with red, green and light blue phosphorescent emitting material were investigated $[3,4]$. E missive layers of red, green and light blue were separated into two emissive units. Various combinations of two emissive units were investigated by spectral simulation in order to obtain high efficiency. It is well known that internal quantum efficiency of phosphorescent OLED was reached to nearly $100 \%$ $[11,12]$. Using light blue emitter to obtain white 
color device, the possible ratio of red, green and light blue intensity can be limited. To obtain white color with maximum internal quantum efficiency in twounit structured device, five possible combinations shown in Fig. 6 have been proposed.

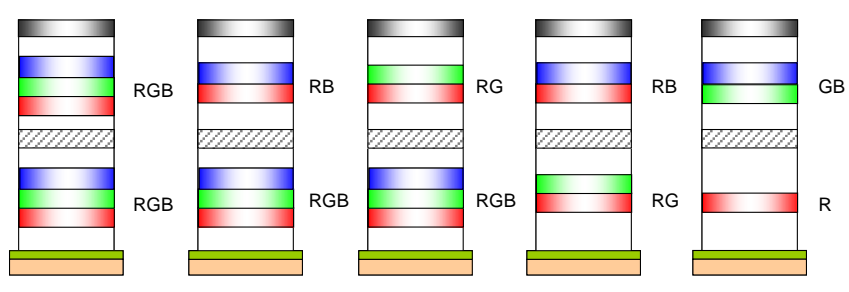

Fig. 6. Various combinations of two-unit all phosphorescent devices with maximum efficiency obtained in white color.

After the experimental examination of various combinations, the two-unit white OLED device with $\mathrm{red} / \mathrm{blue}$ and $\mathrm{red} / \mathrm{green}$ structure was selected. The two-unit device composed of the red/blue and $\mathrm{red} /$ green phosphorescent units was deposited onto the BLES. Fig. 7 shows the structure of high efficiency two-unit all-phosphorescent OLED with BLES; BLES / A node / Hole injection layer (HIL) / Hole transport layer (HTL ) / Red and green emissive layer / Electron transport layer (ETL) / Transparent connecting layer / HTL / Red and blue emissive layer / ETL / Electron injection layer (EIL) / Cathode.

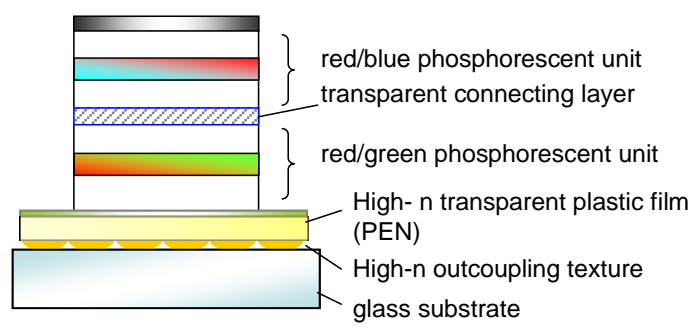

Fig. 7. Schematic of the high efficiency two-unit allphosphorescent OLED with BLES.

Typically, blue phosphorescent host which enables high quantum efficiency has issues in its poor injection and transport properties [12, 13]. Thus, we assumed that blue phosphorescent emitting layer was the main factor of voltage increase. In order to obtain high efficiency of white OLED, low driving voltage red/blue phosphorescent unit was investigated. In this study, the interfacial injection barrier between the electron transport layer and the blue phosphorescent emissive layer was examined. $\checkmark$ arious electron transport materials with different energy levels were investigated and driving voltage was reduced without crucial issue to quantum efficiency and lifetime. M eanwhile, the injection of hole into blue emissive layer was also investigated. These works of career balancing design resulted in successful decrease of driving voltage.

Two-unit all-phosphorescent white OLED devices which were optimized for maximized internal quantum efficiency and lifetime, minimized driving voltage, and proper color coordinates were developed. Low absorption materials, specific light distribution design, voltage reduction technologies as mentioned were also applied. Emission spectrum of this device is shown in Fig. 8. Performance of fabricated devices with $1 \mathrm{~cm}^{2}$ pixel is shown in Table 1.

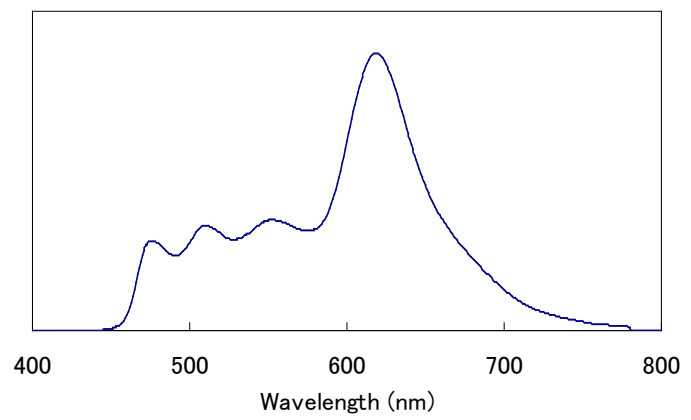

Fig. 8. Emission spectrum of two-unit all-phosphorescent white OLED device.

Table 1. Performance of fabricated all-phosphorescent OLED device $\left(1 \mathrm{~cm}^{2}\right.$ pixel).

\begin{tabular}{|c|c|}
\hline Luminance & $1,000 \mathrm{~cd} / \mathrm{m}^{2}$ \\
\hline Efficacy & $114 \mathrm{Im} / \mathrm{W}$ \\
\hline Driving voltage & $5.5 \mathrm{~V}$ \\
\hline $\begin{array}{c}\text { External quantum efficiency } \\
\text { (estimated LEE) }\end{array}$ & $\begin{array}{c}99 \% \\
(>49 \%)\end{array}$ \\
\hline Estimated lifetime(LT50) & $>120,000 \mathrm{~h}$ \\
\hline CRI & 80 \\
\hline Color coordinates & $(0.48,0.43)$ \\
\hline Color temperature & $2,550 \mathrm{~K}$ \\
\hline
\end{tabular}

Fig. 9 shows voltage-current density characteristics and Figure 10 shows Luminance 
dependence on efficacy. This device realized extremely high efficacy of $114 \mathrm{~lm} / \mathrm{W}$ and quite long half-decay lifetime of over $120,000 \mathrm{~h}$. It also showed $125 \mathrm{Im} / \mathrm{W}$ at $100 \mathrm{~cd} / \mathrm{m}^{2}$ and $102 \mathrm{Im} / \mathrm{W}$ at 3,000 $\mathrm{cd} / \mathrm{m}^{2}$. Over $100 \mathrm{~lm} / \mathrm{W}$ was maintained until high luminance of about $4,000 \mathrm{~cd} / \mathrm{m}^{2}$.

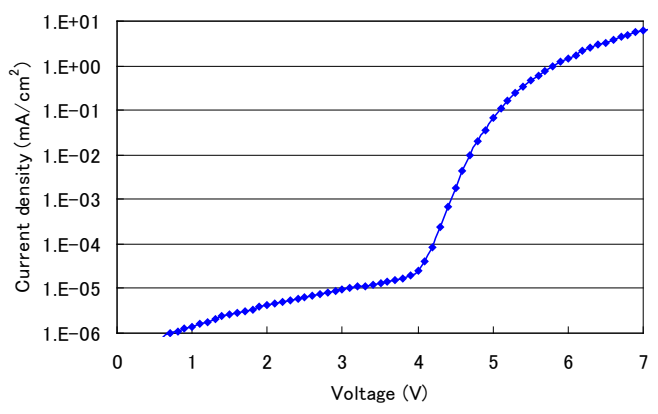

Fig. 9. Current density - voltage characteristics.

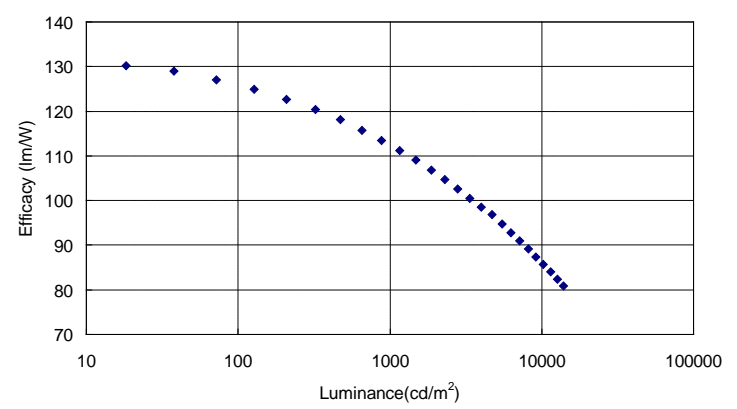

Fig. 10. Luminance dependence on efficacy.

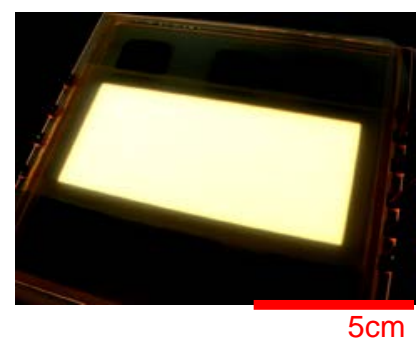

Fig. 11. A ppearance of OLED panel $\left(25 \mathrm{~cm}^{2}\right)$

Then large area OLED device with BLES was fabricated. Emission area was $25 \mathrm{~cm}^{2}$. Uniform emission without dark spots and visible defects was realized as Fig. 11. Properties of this panel are shown in Table 2. Also in this OLED panel, quite high efficacy of $110 \mathrm{Im} / \mathrm{W}$ and long lifetime of $120,000 \mathrm{~h}$ at $1,000 \mathrm{~cd} / \mathrm{m}^{2}$ was observed. Efficacy of the panel decreased about $3 \%$ from pixel $\left(1 \mathrm{~cm}^{2}\right)$ because voltage of panel slightly increased with voltage drop in the circuit or thermal influence. Color coordinates were in the region of white color

Table 2. Performance of fabricated all-phosphorescent OLED panel $\left(25 \mathrm{~cm}^{2}\right)$.

\begin{tabular}{|c|c|}
\hline Luminance & $1,000 \mathrm{~cd} / \mathrm{m}^{2}$ \\
\hline Efficacy & $110 \mathrm{Im} / \mathrm{W}$ \\
\hline Driving voltage & $5.6 \mathrm{~V}$ \\
\hline $\begin{array}{c}\text { External quantum efficiency } \\
\text { (estimated LEE) }\end{array}$ & $\begin{array}{c}99 \% \\
(>49 \%)\end{array}$ \\
\hline Estimated lifetime(LT50) & $>120,000 \mathrm{~h}$ \\
\hline CRI & 81 \\
\hline Color coordinates & $(0.48,0.42)$ \\
\hline Color temperature & $2,600 \mathrm{~K}$ \\
\hline
\end{tabular}

\section{Conclusions}

High-performance all-phosphorescent white devices on a light outcoupling substrate which comprised high-index materials were investigated. The two-unit device composed of the red/blue and red/green phosphorescent units on the light outcoupling substrate achieved quite high efficacy of $114 \mathrm{Im} / \mathrm{W}$ and long half decay lifetime of over $120,000 \mathrm{~h}$ at $1,000 \mathrm{~cd} / \mathrm{m}^{2}$. Key technologies in this device are light extraction efficiency enhancement technology with low absorption materials and optical optimization matched for BLES, and low driving voltage technology with optimization of organic layers without degradation of lifetime. This would be the highest performance ever reported. The arrival of over $100 \mathrm{~lm} / \mathrm{W}$ OLED lighting would be a quite important step of entering into the general lighting market.

\section{Acknowledgements}

This work was supported by New Energy and Industrial Technology Development Organization (NEDO) as "Fundamental Technology Development of Next Generation Lighting of High-efficiency and High-quality" project started in March 2010. We thank to Idemitsu Kosan Co., Ltd. as a member of the project, Universal Display Corporation and NIPPON STEEL \& SUMIKIN CHEMICAL CO., LTD. for their kind provisions of their high performance materials. 


\section{R eferences}

[1] T. Komoda, H. Tsuji, N. Ito, T. Nishimori, N. Ide, SID 10 Digest (2010) 993.

[2] T. Komoda, N. Ide, V. Kittichungchit, K. Yamae, H. Tsuji, Y. Matsuhisa, J. SID 19 (2011) 838.

[3] T. K omoda, K. Y amae, V. Kittichungchit, H. Tsuji, N. Ide, SID 12 Digest (2012) 610.

[4] K. Yamae, H. Tsuji, V. Kittichungchit, Y. M atsuhisa, S. Hayashi, N. Ide, T. K omoda, SID 12 Digest (2012) 694.

[5] Y. Sun, S. R. Forrest, Nature 459 (2009) 234.

[6] M. Slootsky, S. R. Forrest, Optics Letters 35 (2010) 1052.

[7] W. H. Koo, S. M. Jeong, F. A raoka, K. Ishikawa, S. Nishimura, T. Toyooka, H.
Takezoe, Nature Photonics 4 (2010) 222.

[8] S. Reineke, F. Lindner, G. Schwartz, N. Seidler, K. W alzer, B. L üssem, K. Leo, Nature 459 (2009) 234.

[9] R. M a, P. A. Levermore, H. Pang, P. M andlik, K. Rajan, J. Silvernail, M. Hack, J. J. Brown, SID 11 Digest (2011) 983.

[10] P. A. Levermore, A. B. Dyatkin, Z. M. Elshenawy, H. Pang, R. C. K wong, R. M a, M. S. Weaver, J. J. Brown, SID 11 Digest (2011) 1060.

[11] C. Adachi, M. A. Baldo, M. E. Thompson, S. R. Forrest, J. Appl. Phys. 90, (2001) 5048.

[12] M. A. Baldo, D. F. O'Brien, Y. Y ou, A. Shoustikov, S. Sibley, M. E. Thompson, S. R. Forrest, Nature 395, (1998) 151. 